\title{
Methanol Opticaltoxic Neuropathy in Alcoholic Patient: Case Report
}

\author{
Celmir de Oliveira Vilaça ${ }^{1}$, Marco Antônio Araujo Leite ${ }^{1}$, Pietra Moreira Vieira ${ }^{2}$, Fernanda Correa \\ Chaves $^{3}$, Rossano KA Fiorelli ${ }^{3}$, Carlos Eduardo Cardoso ${ }^{3}$ and Marco Orsini*3 \\ ${ }^{1}$ Division of Neurology, Fluminense Federal University (UFF), Brazil
}

${ }^{2}$ Faculty of Medicine, Vassouras University, Brazil

${ }^{3}$ Professional Master in Applied Health Sciences, Vassouras University, Brazil

Received: April 21, 2018; Published: May 07, 2018

*Corresponding author: Marco Orsini, Rua Tavares de Macedo, 95/902. CEP 24220-215, Icaraí, Niterói-RJ, Brazil

\begin{abstract}
The optic neuropathy due to methanol poisoning is a toxic neuropathy most frequently observed in developing countries. It is characterized by acute loss of visual function around 12 to 24 hours after ingestion of methanol. We report a patient with sudden visual loss after deliberate ingestion of methanol seen in a chemical dependency unit of Duque de Caxias, RJ, Brazil.
\end{abstract}

Keywords: Methanol; Vitamin $\mathrm{B}_{12}$; Alcoholism

\section{Introduction}

Methanol is a colorless, flammable liquid with a slight alcoholic odor. It is used in automotive fuels, solvents, antifreeze fluid, cleaning products and adulterated alcoholic beverages [1,2]. Methanol has a taste and odor similar to ethanol and it is impossible to differentiate ethanol during ingestion [3]. Signs of methanol intoxication usually begin after 12 to 24 hours after ingestion, with metabolic acidosis associated with increased anion gap and visual disturbances [4]. More rarely there are cases of intoxication by their inhalation in certain branches of professional activity or transdermal intoxication [5]. Methanol itself does not produce toxicity, resulting from its transformation into formic aldehyde and formic acid by the enzymes alcohol dehydrogenase and aldehyde dehydrogenase respectively. This fact explains the delay from its ingestion to the beginning of clinical symptoms. These are characterized by headache, nausea, and vomiting, visual loss and in severe cases coma or death with marked metabolic acidosis [6].

\section{Case Report}

Patient of initials P.R.P, 51 years old, married, a son, with incomplete high school degree, worker in the refrigeration field. He was being treated in the unit due to a history of alcoholism and smoking associated with cocaine abuse and sporadic use of crack. Two years earlier, before starting treatment in the unit, after an episode of alcohol abstinence he deliberately ingested undetermined amount of methanol that was being used in his work, diluted in water. Less than 24 hours later, headache and vomiting were associated with constriction and turbidity of the visual fields followed by bilateral amaurosis. He did not look for an emergency unit after the event, and there was no worsening or subsequent regression of the condition. He then began to complain of complex visual hallucinations, with visions of naked women, skulls and rodents.

Due to the limitation imposed by visual loss, he decreased substance abuse with the help of family members. At the time of the neurological evaluation, he had been abstinent from alcohol for more than 90 days. He was under the use ofrisperidone 1mg/ day, diazepam $10 \mathrm{mg} /$ day and carbamazepine $200 \mathrm{mg}$ /day with control of alterations of sensoperception. Neurological examination demonstrated isocoria, with medium-sized and non-photoreacting pupils, bilateral optic atrophy in the funduscopy, and reduction of the achileu reflex bilaterally associated with decreased pain sensitivity in the lower limbs. The mental state was normal and, despite the visual dysfunction, he kept critical judgment, with self and alopsychic orientation. The remaining clinical examination was normal. During the follow-up period in the unit, the patient was also diagnosed with vitamin B12 deficiency below 200pg/ml currently under replacement. He is also being accompanied by an external 
ophthalmology service. Therefore, he underwent retinography with fluorescein showing bilateral optic atrophy (Figure 1). Also performed retinal optical coherence tomography with a decrease in the layer of nerve fibers in the right eye, and it was impossible to reliably measure the left retina using such technique (Figure 2).

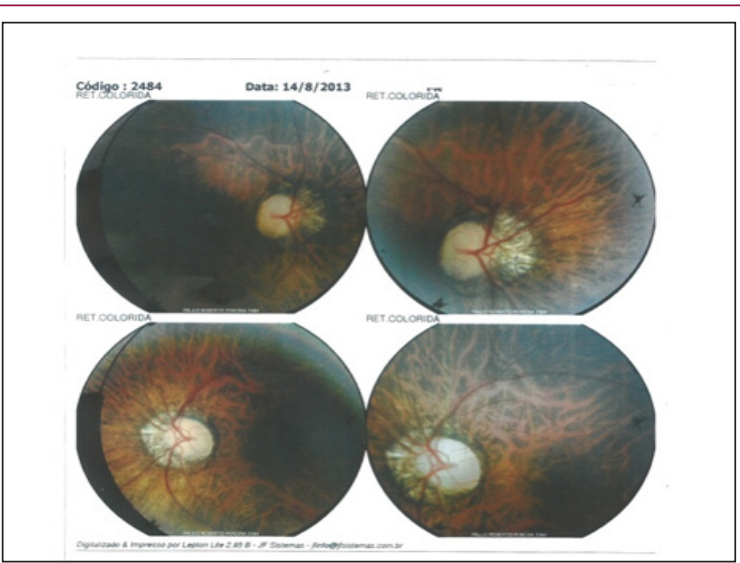

Figure 1: Retinography with fluorescein showing bilateral optic atrophy.

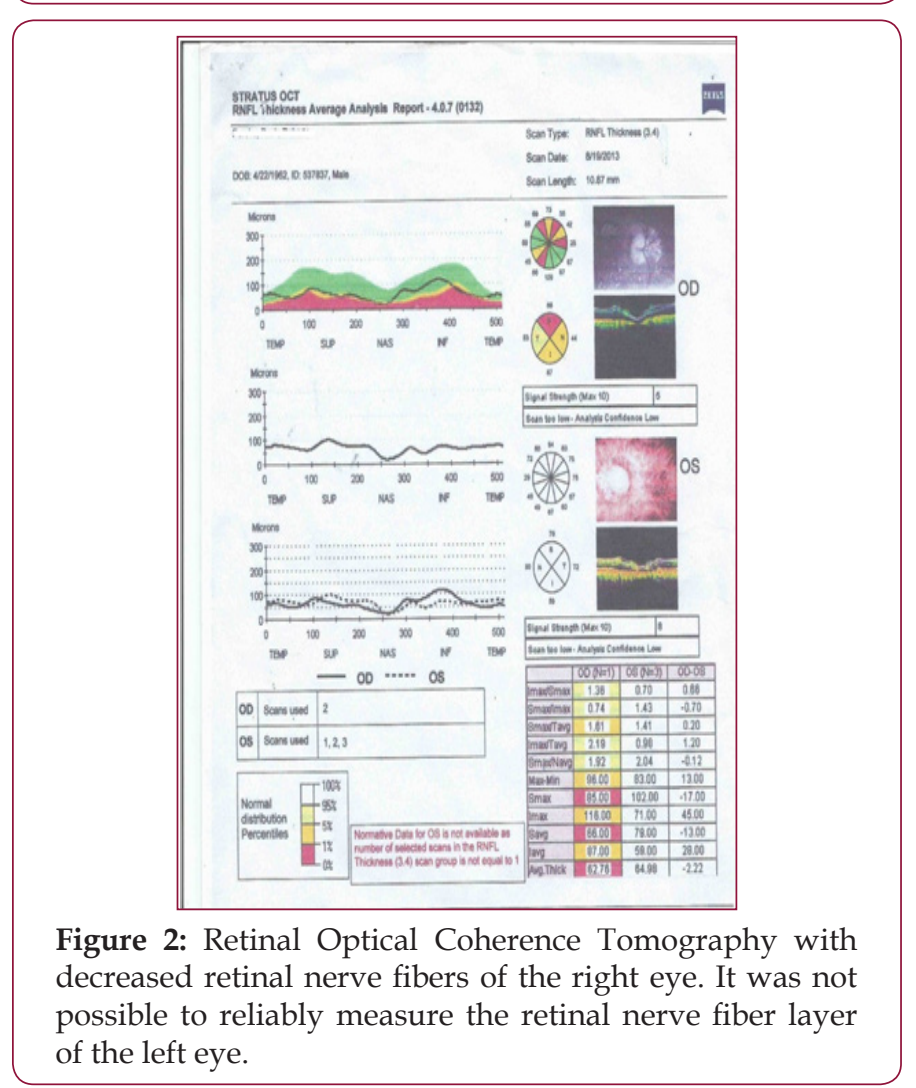

\section{Discussion}

The minimum methanol dose required to cause permanent visual changes is unknown, but visual loss with doses as low as $4 \mathrm{ml}$ has been reported [7]. Serum concentrations above 50mg/ $\mathrm{dl}$ are associated with severe metabolic acidosis with increased anion gap and risk of coma or death [4]. Methanol intoxication, while classically causing acute visual loss, can lead to a combined condition of Parkinsonism due to necrosis of the nuclei of the base, especially in the putamen. Similar conditions with anatomical putaminal injury occur in other intoxications where there is histotoxic hypoxia such as in carbon monoxide poisoning, postoperative hypotension, hypoglycemia and cardiac arrest [8]. Less commonly, methanol causes peripheral neuropathy. However, in the case reported, neuropathy is more likely to be related to the condition associated with alcoholism, and vitamin B12 deficiency currently under treatment [6].

Formic acid produced by metabolizing methanol leads to metabolic acidosis and inhibition of the cytochrome $\mathrm{C}$ oxidase enzyme in the mitochondrial respiratory chain. This leads to hypoxia of the oligodendrocytes and astrocytes around the optic nerve with cell lesion even in the absence of detectable vascular damage [1]. Optical Coherence Tomography (OCT) is a non-invasive imaging technique for analysis of the retinal nerve fiber layer with high resolution. There are researches with OCT in degenerative diseases such as Alzheimer's, Parkinson's disease and Multiple Sclerosis [9]. Used experimentally in the evaluation of toxic optic neuropathy by methanol usually shows edema of the nervous fibers in the acute phase of intoxication and diminution of the nerve fibers in the chronic phase [10]. B12 deficiency diagnosed could also alter the OCT with decreased nerve fibers findings such as in methanol intoxication [9].

Nuclear magnetic resonance imaging (MRI) of the skull is not normally used. When performed in the acute phase of intoxication may present normality in the T1 e T2 sequences. However, it may evidence contrast uptake or alterations in the diffusion sequence in the retro bulbar segment of the optic nerves [3]. There are cases of methanol intoxication with blindness associated with unilateral contrast uptake in MRI [11]. Treatment in the acute phase of methanol intoxication is essential for the preservation of visual function. In the acute phase the therapy can be done with fomepizole, an alcohol dehydrogenase inhibitor, preventing the formation of formic acid, however this is not available in Brazil [12]. One can use IV ethanol for competitive inhibition of the binding of methanol to alcohol dehydrogenase as well as bicarbonate for correction of acidosis [13]. Hemodialysis can be used in cases of intoxication with serum levels higher than $20 \mathrm{mg} / \mathrm{dl}$, intake of a dose higher than $30 \mathrm{ml}$ and there is no improvement of acidosis despite the use of bicarbonate [2].

In the acute phase, administration of IV erythropoietin may also be attempted to improve visual impairment. Erythropoietin decreases the number of lesions due to oxidative damage by increasing the activity of glutathione peroxidase and superoxide dismutase. Replacement of erythropoietin also promotes axonal and retinal ganglion cell survival [12]. Some authors recommend pulse therapy with corticosteroids in high doses [1]. Thiamine by reversing the effects of intoxication by ethyl alcohol and by analogy is also used in methanol intoxication [14]. Folic acid is also used in an attempt to increase hepatic metabolism of formic acid in $\mathrm{CO} 2$ and water $[4,6]$. Most reported cases of methanol intoxication did not measure serum vitamin B12 levels. Other reports administered folic acid as a treatment not associated with B12 replacement. Folic acid may cause decreased cobalamin reserves [15]. Regardless 
of the type and time of exposure to methanol, we always suggest the replacement of vitamin B12, especially when there is folic acid replacement.

\section{References}

1. Abrishami M, Khalifeh M, Shoayb M, Abrishami M (2011) Therapeutic effects of high-dose intravenous prednisolone in methanol-induced toxic optic neuropathy. J Ocul Pharmacol Ther 27(3): 261-263.

2. Onua A, Nwadiuto I, Pedro Egbe C (2016) Bilateral Optic Atrophy Following Methanol Poisoning: A Case Report. Br J Med Med Res 18(5): 1-6.

3. Tanrivermis Sayit A, Aslan K, Elmali M, Gungor I (2016) Methanolinduced toxic optic neuropathy with diffusion weighted MRI findings. Cutan Ocul Toxicol 35(4): 337-340.

4. Bucaretchi F, De Capitani EM, de Madureira PR, Cesconetto DM, Lanaro R, et al. (2009) Suicide attempt using pure methanol with hospitalization of the patient soon after ingestion: Case report. Sao Paulo Med J 127(2): 108-110.

5. Souza FGT, Nogueira VVE, Maynart LI, Oliveira RL de, Mendonça TC dos $\mathrm{S}$, et al. (2018) Optic neuropathy toxic after methanol inhalation. Rev Bras Oftalmol 77(1): 2017-2019.

6. Mangaraj S, Sethy G, Sen R, Rout R (2014) Methanol poisoning induced acute onset Parkinsonism, optic neuritis and peripheral neuropathy in a patient. Int J Med Public Heal 4(1): 130-133.

7. Bellarinatasari NH (2011) Toxic Optic Neuropathy Due to Metanol in Dr. Sardjito Hospital (Lapen Intoxication) Case Series Kasus Neuropati
Optik Toksik karena methanol di RSUD dr. Sardjito (Intoksikasi Lapen) Studi Kasus. Sains Med 3(2): 177-184.

8. Carrete H, Nogueira RG, Abdala N, Nalli DR (1994) Tomografia computadorizada na intoxicação por metanol: relato de caso. Arq Neuropsiquiatr 52(1): 93-95.

9. Türkyılmaz K, Öner V, Türkyılmaz AK, Kırbaș A, Kırbaș S, et al. (2013) Evaluation of peripapillary retinal nerve fiber layer thickness in patients with vitamin B12 deficiency using spectral domain optical coherence tomography. Curr Eye Res 38(6): 680-684.

10. Fujihara M, Kikuchi M, Kurimoto Y (2006) Methanol-induced retinal toxicity patient examined by optical coherence tomography. Jpn J Ophthalmol 50(3): 239-231.

11. Lu JJ, Kalimullah EA, Bryant SM (2010) Unilateral Blindness Following Acute Methanol Poisoning. J Med Toxicol 6(4): 459-460.

12. Pakdel F, Sanjari MS, Naderi A, Pirmarzdashti N, Haghighi A, et al. (2018) Erythropoietin in Treatment of Methanol Optic Neuropathy. J NeuroOphthalmology p.1-5.

13. Schneeweiss S, Rassen J (2011) Letter to the editor. Pharmacoepidemiol Drug Saf 20(10): 1110-1111.

14. Rotenstreich Y, Assia EI, Kesler A (1997) Late treatment of methanol blindness. Br J Ophthalmol 81(5): 416-417.

15. Johnson MA (2007) If high folic acid aggravates vitamin $B_{12}$ deficiency what should be done about it? Nutr Rev 65(10): 451-458. (c) (7) This work is licensed under Creative Submission Link: https://biomedres.us/submit-manuscript.php

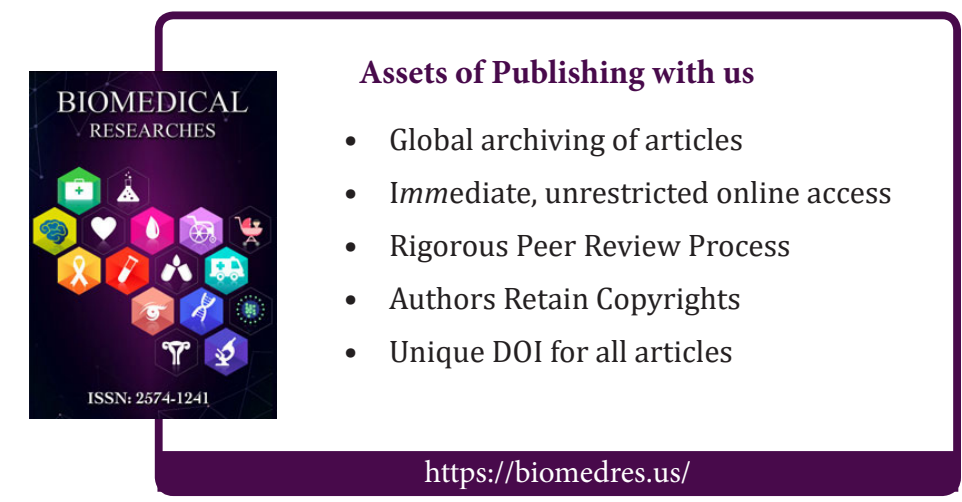

